\title{
Research Capacity Building for Clinicians: How Does the Research Facilitator Role Foster Engagement in the Research Process?
}

\section{Tracy Flenady ( $\sim$ t.flenady@cqu.edu.au )}

Central Queensland University https://orcid.org/0000-0002-5286-4789

\section{Trudy Dwyer}

Central Queensland University

Julie Kahl

Central Queensland Hospital and Health Service

Agnieszka Sobolewska

Central Queensland University

Kerry Reid-Searl

Central Queensland University

\section{Tania Signal}

Central Queensland University

\section{Research}

Keywords: Research capacity building, novice researcher, research facilitator, clinician researcher

Posted Date: January 21st, 2022

DOI: https://doi.org/10.21203/rs.3.rs-1216750/v1

License: (1) This work is licensed under a Creative Commons Attribution 4.0 International License. Read Full License 


\section{Abstract}

Background: There is evidence reporting more positive outcomes from research capacity building programs that include a research facilitator role. Further, it has been suggested that research facilitator roles can be a useful strategy in building the research capacity of health care clinicians. However, until now, little attention has been applied to identifying the characteristics of the research facilitator role and how this role contributes to clinicians' engagement with the research process.

Methods: This qualitative study employed an inductive approach and utilised face to face interviews to gather data from a purposely selected cohort. Professionally transcribed responses were thematically analysed.

Results: The role of the research facilitator emerged as comprising two main themes: 1) Facilitating the research process and 2) Engaging expert clinicians as novice researchers. Pragmatically, analysis of data led to the development of a table outlining the responsibilities, skills and attributes related to each theme. Conceptually, theme 1 encapsulates the Research Facilitators' skills and experience and their role as knowledge brokers and co-creators of knowledge. Theme 2 provides insight to the clinician-centric approach the RFs utilised to build and foster relationships and support the clinicians through their research journey.

Conclusion: This study reports on the characteristics of the research facilitator role in a research capacity building (RCB) program in one regional health service district in Australia and explains how the role fosters clinicians' engagement with the research process. Findings from this study will inform the development of future RCB programs, which is important when you consider that clinicians' increased engagement with the research process is vital for developing a sound evidence base to support decisionmaking in practice and leads to higher levels of skills and greater ability to perform useful research.

\section{Background}

Despite advances and innovation in health care and health care research, a gap between research and practice remains, with evidence to suggest it takes an average of 17 years for clinical research evidence to reach clinical practice $(1-3)$. Considering only 60 per cent of treatments provided by clinicians are evidence based, research capacity building (RCB) of clinicians is a priority if we are to narrow the research-practice gap (4). RCB is defined as a '...process of individual and institutional development which leads to higher levels of skills and greater ability to perform useful research' (5). Capacity building of clinicians can range from gaining an appreciation of the value of research, keeping up to date with the research to applying findings in clinical decision-making processes (6), Additionally, capacity building can progress to knowledge creation and conducting clinical research that has the potential to enhance the quality of patient care (7) and ultimately, embed discovered knowledge into practice (Graham et al 2006). However, the relationship between knowledge discovery and implementation is iterative and embedded in healthcare practice $(8,9)$. 
Health care is not only the consequence of research but is also the setting for research, in a close relation to, and iterating between, health care and health research (9). At the coal-face, clinicians have the most practical understanding of issues important to practice (10) and exposure to research that addresses these problems results in greater questioning of the literature and current practices (10). Despite clinicians being well positioned to be active in doing research and not simply being the recipients and potential users of research, a lack of research expertise is a significant barrier for clinicians doing research $(11,12)$. Increasingly, health services are engaging research academics to facilitate the research capacity building of clinicians (13-15).

Implemented hospital based RCB initiatives of clinicians typically involves partnerships between universities and hospitals $(13,16)$. These may include the provision of educational research support, small research groups and academic research facilitators who act as mentors providing support and advice to design and carry out research projects. Such programs contribute to the development of a positive research environment, directly impacting in patient care $(14,17)$. While these examples offer a helicopter-view of the usefulness of research facilitator in building the research capacity of clinicians, the attributes of successful research facilitators are not well described in the current literature (18). Our study sets out to examine the contribution of the research facilitator role in one research capacity building program and identify the characteristics of the research facilitator role to understand how this role contributes to clinicians' engagement with the research process.

The RCB program specific to this study, referred to as the Research Ready Grant Program (RRGP), was established in 2018 and can best be described as a multifaceted and multidisciplinary RCB program developed to facilitate collaborative multidisciplinary practice-research partnerships. The RRGP incorporates principles for successful capacity building as presented by Cooke (6). The program specific to this study consists of self-selected multidisciplinary teams of health professionals and multiple organisations (two universities and a hospital health service) working together to increase research capacity at the individual, team and organisational level. Multi-disciplinary professionals from within the organisations work together to conceive a research idea that meets the organisation research strategic plan. The organisational level partners come together to provide the research mentor for the teams and form the RRGP committee to oversee the implementation of the program.

The RRGP consists of two phases. Phase one comprises an eight-week series of educational workshops where multidisciplinary teams work together, and with the support of a research facilitator, turn a clinical problem into a researchable question and then develop a research proposal around that topic. Phase two involves a competitive, peer reviewed, grant submission process whereupon teams from phase one submit their developed research proposals and vie for funding to operationalise their research proposal. As research supervision and mentorship are intrinsic to the successful completion of research projects (19), successfully funded teams are provided with mentor support for the duration of their project.

The RRGP is funded jointly by the health facility and university and is delivered annually across a health service district in regional Australia. The RRGP engages research facilitators as a core component of their 
RCB program. This study examines the experiences and perspectives of the research facilitators attached to the RRGP over a two-year time frame to gain insight into how an embedded research facilitator role within a RCB program facilitates clinician capacity and engagement in the research process.

\section{Methods}

Aim

This study aimed to explore the characteristics of an embedded research facilitator role in a research capacity building program to develop an understanding of how this role contributes to clinicians' engagement with the research process.

Study design

This qualitative study employed an inductive approach and utilised interviews to gather data from a purposely selected cohort. Transcripts of all responses were thematically analysed.

Subjects and setting

To be eligible, participants must have fulfilled the role of a research facilitator in the nominated RCB program.

Data collection

Nine research facilitators (five females, four men) were interviewed, representing all the research facilitators participating in the RCB program across two years. The interviews were conducted between late October and early December 2019. All interviews were recorded and later transcribed by a professional transcription service. During the interview, the following research questions were explored:

- How does the Research facilitator role contribute to building research capacity among clinicians?

- What attributes and skills does the Research facilitator role require and why?

- Does the research facilitator role contribute to participants engaging with research? If so, how and why?

\section{Data analysis}

Utilising Braun and Clarke (20)'s thematic analysis methods, each transcript was coded, with text extracts copied and pasted under the relevant coding categories into a word document created for data analysis purposes. Data were then organised into categories in search for themes or patterns. The generated themes were then reviewed in a two-fold process. Firstly, the research team examined the themes at the level of the coded data extracts. Secondly, the team reviewed the themes in relation to the data set and considered if the themes reflected the meanings evident in the data set, all the while considering the themes in relation to each other. When consensus was achieved on final definitions of themes, the 
resulting themes were named. Finally, the results of this thematic analysis were written up and are presented in the following section.

\section{Results}

Following data analysis Facilitating the research process and Engaging expert clinicians as novice researchers emerged as the main themes that explain how the research facilitator role facilitates the capacity of clinicians to engage with the research process.

Theme 1: Facilitating the research process

During the interviews, the research facilitators were asked about the skills and attributes they believe are important to the research facilitator role. Table 1 lists the responsibilities, skills and attributes that research facilitators identified. The responsibilities relate to the scope of the research facilitator's role over an eight-week period or the duration of phase 1 of the RRGP in working with clinicians to help them develop research proposals. The identified skills relate to theoretical and practical understanding of research methods as well as designing and conducting research projects. Attributes relate to the acknowledgement among the research facilitators that it is unrealistic for an individual to have all the answers and that the role entails facilitating links with other research experts and appropriate resources. 
Table 1

Responsibilities, Skills \& Attributes for Facilitating the Research Process

\section{Responsibilities}

- Working with clinicians as novice researchers to help them develop research proposals

- Simplifying the research process

- Answering general questions about research

- Discussions with clinicians about what they learnt in the lecture meant for their study

- Improving practice ideas and concepts into study

- Breaking down projects into feasible ones

- Providing support on how to formulate research questions, identify gaps, choose suitable study methods

- Working with groups with different levels of research knowledge

- Keep participants on track

- Research facilitators as resources: linking up with people, linking to appropriate resources
Skills

- Experience in research design and the fundamentals of conducting a research project

- Qualitative or quantitative research design experience

- Completing ethics, hospital ethics

- Research project management required - budget, human resources, how to achieve each milestone in a timely manner

- Can identify issues that come up with research

- Understanding clinical research

- Ethics applications

- Grant applications
Attributes

- Conduit - a link between providing information to clinician

- "I am not a cancer expert, but..."

- Understanding own limitations as to how the research facilitator can contribute to the group

- Overcoming the gaps in personal areas of expertise when dealing with different research groups

Research Skills and Experience

The research facilitators brought their research experience into their roles. Participant 3 provided an overview of the general research characteristics of the RRGP research facilitators as a group: [they have] "... a good mix of highly experienced researchers, with many years of publication, working with health services, getting external funding, and so on, through to some early career researchers, who are highly enthusiastic about the things that they do, and really want to drive research in the same way that they were probably mentored as novice researchers in their early days". At a minimum, the research facilitators are early career researchers with a focus on health services.

Research facilitators spoke about having the theoretical research knowledge coupled with the practical experience of conducting research. Participant 4 listed the skills and experience required for the role: “... 
experience in research, conducting a range of different research projects so that the research facilitators have had experience addressing issues that come up - or identifying the issues that might come up in research, to help the clinicians to be aware of that and minimise the risk of those things happening in their own research. To be aware of different methods, research methods out there, that they could draw on to answer their research questions". Participant 2 also named the practical skills of project management including understanding of "budget, the timeline, how to allocate the human resources and how to achieve each milestone in a timely manner".

Making Sense of the Research Process

The research facilitators saw their role as simplifying the research process. In Participant 9's words, the role entailed: "... support[ing] the clinicians and to help them think about the research process. So to step them through the very basics of how do you develop a research question, all the way through to really nailing down the research design". Each week, research facilitators had conversations with the teams of clinicians about how the content presented at the one-hour lectures preceding the workshops related to their particular research projects. Participant 2 described the process as involving "make[ing] sense of concepts.... not using so many jargons". Participant 4 elaborated: "...there were a lot of unique studies [with] very unique sorts of issues that hadn't necessarily been covered in the lectures, so the research facilitators were there to help".

Research facilitators offered guidance with developing feasible and achievable research proposals. The guidance included as Participant 6 described: “...make[ing] sure that they use an appropriate design method, and data collection and data analysis methods... ethics is very important". Research facilitators recalled a trend of clinicians entering the RRGP with a mindset of wanting "to save the world". The implication for the research facilitators' role was that the research ideas were often too large and complex for the scope of the RRGP. Participant 5 recalled: "very often I had to pull them back... my biggest challenge was convincing them that it was just really more of a pilot project and a small project that they were looking at". Similarly, for Participant 3, facilitation entailed "breaking it down into something that is feasible". Research Facilitators' narratives suggest that they did not give directives but offered guidance in helping clinicians to make informed choices around designing achievable projects. Participant 6 reflected: "I tried to show them how long did it take me to be able to collect my data. That was like an experience that I shared, and they understood".

Understanding the clinical context for conducting the research projects was flagged as important by some. Participant 6 advised that with clinical research, "there's an extra barrier, because you're always thinking about patients, you're always thinking about their safety and... it's another obligation that you have to follow". Participant 7 identified that the research facilitator's role focus on "... reinforcing the processes of research, rather than the actual details of how to conduct it within their particular hospital system" was a limitation. Participant 7 argued that "there needs to be somebody who could potentially assist in that clinical situation, or understanding clinical context... somebody who's within the health system or within the hospital system, to negotiate some of those questions that arise that are very 
context specific to health and to the hospital". Participant 7 argued that this clinical guidance could especially be fundamental for preparing successful projects' ethics applications to the hospital's ethics committee.

Knowledge Brokers

The role of a Research facilitator emerges as that of a knowledge broker. Research facilitators as research experts in specialized fields, openly acknowledged their limitations in advising on all research matters. Participant 5 expressed: “...there were times where I felt my expertise wasn't matched enough and I could see that they [clinicians] needed that help... If they asked me specific questions, I'd say look I'm not an expert in breast cancer, but as an overarching research project this is how that would normally be handled". While being able to provide general guidance, the research facilitators connected the clinicians with other researchers that had the relevant expertise when required. Participant 8 expressed: “... if I wasn't competent with a group, or if I didn't know what they were doing, then I would always get external support". Research facilitators spoke about connecting clinicians with other RRGP research facilitators around research design issues. Participant 9 elaborated: "...my background is very much in quantitative research and if someone is looking at doing something from a qualitative perspective, there are other research facilitators who are more experienced in those qualitative methodological approaches... I would link them up within one of the other research facilitators that had more experience than I did, to be able to guide that expertise in that qualitative space". At times, research facilitators provided links to resources. Participant 1 spoke about doing follow up work in between the workshops: "... I might even do a little bit more research myself. Then take that information to the workshop the following week and just give it. Or email out afterwards".

Co-creating a Positive Research Culture

There was a shared recognition of the RRGP driving the research culture long term. Participant 3 expressed: "...it's not just about that one, individual project, but it's the bigger picture of the relationship between the health service and the university". Similarly, Participant 7 observed: "RRGP program is adding to being able to enhance the amount of research that's coming out of the hospital ... it can only be of benefit in improving clinical practice within the hospital but also more broadly". As the RRGP is nested within the organisational structures and aligns with the strategy to increase the capacity of the health service to conduct research, it is designed as a longer-term investment around research capacity building of the clinicians.

The eight-week program is thought to be foundational to creating research culture. Participant 8 reflected that if clinicians fully engaged and regularly attended the RRGP: "...it (the skills development program) boosts their awareness of research. It boosts their social interaction with other likeminded people that are doing the same thing. It boosts their knowledge of all the foundations of research". In participant 4's experience: "...the clinicians were able to identify immediate needs for research in the real world and to be able to use my skills to help... to draw up a plan to be able to address that need and do research to solve that problem". Participant 1 observed: "I hear the language change in their voice when they start to talk 
about it [research]. I really think that once they understand how engaging with research impacts their professional role, and their ability to effect change, really, and how they can incorporate what they've researched into their everyday practice, I don't think they can turn back". Participant 3 elaborated on the potential of a bottom-up effect in the diffusion of the research culture on the peer-to-peer health service level: "...they [the clinicians] can then go off and go, okay, we learnt these skills in the previous project, how can we apply that to something new, that we might want to do, without being part of the project... They can then inspire... others that, yeah, you know what, research actually isn't such a bad, nasty, scary thing to do, that others might at least be willing to join the program and have a go at it".

The RRGP was a platform for knowledge exchange between health services and academia. Participant 4 expressed the value of seeing the fast progression of the real-world research process in contrast to academic research which can be slow in terms of dissemination and getting the translational impact. Participant 9 expressed reward from being 'a part of translating research to practice". Participant 6 reflected: "...there were problems that I've never thought of. There were solutions that I've never thought of ... because every discipline has their own viewpoints, there were discussions at the table [a lot of], I guess a lot of advantages in terms of me understanding what my future research, in terms of clinical research, can be". Participant 6's comment mirrors the sentiment expressed by other Research Facilitators, not only about the professional value in learning about the current issues in health care, but also in being part of envisioning new approaches for investigating and solving these issues through research.

Theme 2 Engaging expert clinicians as novice researchers

Engaging expert clinicians as novice researchers emerged as a major theme in narratives about the skills and attributes that RRGP research facilitators require if they are to build research capacity of clinicians who are acknowledged discipline experts and yet, novices when it comes to conducting research. Table 2 shows the responsibilities, skills and attributes related to this theme that research facilitators identified. These relate to group work and clinician-focused facilitation methods which were purposefully applied to engage clinicians in the research process. 
Table 2

Responsibilities, Skills \& Attributes for Engaging expert clinicians as novice researchers

\section{Responsibilities}

-Assess the needs of each research team and the group as a whole

-Manage multiple research groups

-Assess understanding of the weekly topic and workshop the topic

-Check for misunderstandings

-Facilitate conversation in a safe space

- Making material relatable on professional and personal level

-Encourage reciprocity of learning between the different participants

-Provide written examples, exercises, extra resources, homework

-Work with research emotions of the clinicians

- Listen to clinicians as to what they want to do rather than impose own bias

-Keep the enthusiasm for research

-Instil confidence

- Getting to know participants personally and how they react to certain questions and content to support them accordingly

-Working with negative emotions and emotional reactions to research

-Breaking down professional hierarchies if applicable
Skills

-Motivational interview to help clinicians clarify a clinical problem into a research question

- Using the collective wisdom of the group

-Being able to see deficits in learning and learning needs

- Good understanding of adult learning concepts

- content delivered in easily digestible ways

-Outstanding communication skills

-Active listening

-Looking and observing

-Clinician background of research facilitators can be useful

-Allowing everyone to have a voice

-Understanding communication cues

-Developing rapport

-Organisation skills to manage multiple projects, time management organisational skills

\section{Attributes}

-Open mind

-Being adaptable - absorb information quickly

-Being aware of own biases and ensuring that they don't interfere (e.g. spending more time with groups with shared topic expertise)

-Transparency and authenticity to meet the clinicians' expectations

-Enthusiastic approach

-Being approachable 
Working with clinicians as novice researchers involved working with their clinical expertise. While research facilitators indicated that the research skills among clinicians were variable due to the absence or limited research training, clinicians had the necessary clinical expertise. In Participant 3's words, the clinicians "see these research worthy things on a day-to-day basis... they participate in the research by really leading the design... I would lean on their knowledge and experience". The presence of practiceresearch continuum would emerge from the Research Facilitators' narratives. Participant 2 reflected: "the clinicians have a lot of information ... from their own experiences, but they don't know how to test this knowledge, how to test their assumptions". The research facilitators work with the complementary clinical and research roles. Participant 2 explained: "there is sufficient knowledge base [that] ... require[s]... to translate this knowledge to experiment in the research ... Naturally we all are researchers. We always think rationally, we think logically". Participant 6 noted a difference between research and clinical work: "clinicians always follow the guidelines and the rules... Those guidelines and processes are not always clear in research".

Clinicians and their projects bring strengths to the research-practice continuum. Participant 2 observed: "most of them (RRGP research projects) are clinical studies. The participants are clinicians... so, they know their projects". Participant 1 also noted that: "participants are already motivated to come on their own time ... which means that they want to be there and work through the problems... The goal at the end of the eight weeks is to have a fully developed research proposal, and all of the teams did that. So that shows that they engaged with the process properly and that the Research facilitator aided in their understanding of the material".

Clinician-Centred Approach to Facilitation

Clinician-centred approach to facilitation was evident throughout the narratives. Research facilitators spoke about their focus on understanding and meeting the needs of the clinicians. Participant 1 commented: "it's my job to really assess the needs of each of the teams individually as well as a whole... pick up early any misunderstandings that they've got... Then extrapolate more on areas of the topic that they are showing a poor understanding". Research facilitators spoke about using active listening and observational skills to guide their assessment. Participant 1 explained: "I listen to the questions they ask and encourage them to speak amongst themselves... but I really listen to the questions, and how they're interacting around the topic". Participant 5 further noted: "...you can just see in their body language that they're struggling with a topic".

Research facilitators spoke about exercising awareness of own research bias and minimising it. Participant 4 gave an example from working with one clinician: "I saw lots of interesting studies and wellcontrolled studies but the questions that she [the clinician] was asking - was wanting to ask based on her experience were just different to what I thought would be interesting". Participant 4 spoke about importance "to listen to the clinicians themselves as to understand what they are really wanting to research and what questions they want to answer without putting on our own interests of a research role or our own area that we specialise in". Research facilitators used adjectives such as being open, honest, 
frank, transparent and authentic in their clinician-centred approach. For Participant 3, being open involved using: "... a motivational interviewing style, I guess, to help them [clinicians] clarify what they see as research worthy, and turn that into a research question ... asking lots of seemingly naive questions, about why that's important, and what are the implications of that and what's been done about that in the past, and how does that fit with the working group that they're attached to, and so on, so that I can get a clearer picture of what it is they're trying to achieve and why".

Building and Fostering Relationships

Building and fostering relationships between the research facilitators and the teams, as well as between team members was part of working with the clinicians to help them achieve research goals. In Participant 1's words: "relationships are crucial to the learning process". There is a sense that through the relationship, research facilitators gained awareness of the learning needs of the clinicians. Participant 5 reflected: "...you get to know them personally quite well, so you get to know what they're going to be worried about and how they learn and react to certain questions". Participant 5 further indicated these relationships would guide how she structured the social environment for learning: "...often people felt a little bit uncomfortable talking in front of that big group... the tactic I used ... was to get them then into their own individual groups and then I would rotate around. one of the other research facilitators gave more of a lecture style workshop, like a tutorial, to the whole group, but that wouldn't have worked for me because they [project teams] were very different [from each other]'.

Relationships within and between teams were conducive to reciprocity of learning among the clinicians. Participant 8 described the typical composition of the RRGP research team: "...people in different departments, or different disciplines, that are likeminded ... and have the same goal, with the same research idea". Participant 6 emphasized that the multidisciplinary teamwork "...caused some good debates ... which helped them to understand there are different barriers, and they can find a way... to overcome that barrier and solve those problems". Participant 8 pointed to the usefulness of the question: "what would you do from a [discipline-specific] perspective?" to elicit problem exploration among the different disciplines and to "mould their multidisciplinary team project into a nice, collegial project that can benefit all professions". Participant 1 saw the group discussions between the teams as enhancing adult learning. She observed: “...everybody's hearing everybody else's responses, and it's growing their understanding of it as well, and covering off on questions that perhaps they might have had anyway, which gives them the opportunity then to think more and extend their understanding of it and ask another question".

The research facilitator's role at times required in Participant 5's words to "build capacity between the different members of the group". Participant 3 elaborated: "you have a group or an individual that was... dominant in some particular way, then the success of that large group would have relied on the skills of the Research facilitator to acknowledge that expertise but ensure that expertise was usefully directed to the group as a whole". For Participant 5, facilitation involved shifting the "imbalance of power" in a team where the interprofessional hierarchy dynamics were playing out. Participant 5 spoke about "facilitating 
the conversation in a safe space... ensuring that there was equal space and time for each of the participants". She observed that this process encouraged "listening to different people's opinion" and "facilitated a "natural evolution" within the first part of the RRGP workshop phase. Participant 5 observed that the particular group "became much more open" and "a certain group of people were allowed to voice their opinion more strongly and have some say in the direction of their project".

Supporting clinicians through their research journey

"Keeping the participants on track" was the phrase used by research facilitators to convey the practical focus of their work. In Participant 5's experience, the teams "would go away each week and they'd come back with completely different ideas. A lot of the beginning parts of the session was getting them back to being... on the same page". Over the course of the RRGP skills-development program, the research teams would also make different progress towards their research project proposals. Participant 7 reflected: "each of those groups are so different in what they're doing, it's very difficult to provide just a single comment about something to address everybody's needs". Research facilitators would allocate their time accordingly among their research groups. Participant 8 indicated that "dividing your time relatively evenly between the groups is sometimes a little bit tricky when you've got some groups that you're very experienced in and so you can offer a lot more to that group because of your background experience".

Responding to the needs of the clinicians' research groups was not overly complex. Research facilitators drew on their academic experience related to their organisational skills and adaptability. Participant 8 explained: "we do that [manage multiple projects] with different PhD students, with different teaching into different units... often balancing our time between different things and different projects, and writing our own research, writing our own grants". Similarly, Participant 5 identified the usefulness of her "academic experience working with other researchers, doing some lecturing, being thrown in the deep end... to be adaptable and be able to absorb information quickly and then tilt it to how you need".

Working with a broad range of clinicians' emotions at different stages of the RRGP skills development phase emerged from the narratives. Research facilitators' commonly spoke about clinicians' enthusiasm and saw it as an energising force. In Participant 1's words, the group's enthusiasm was "contagious and exciting". However, frustration, fear, being overwhelmed, anger and disappointment have also surfaced. Participant 6 spoke about debunking the misconceptions about research at the beginning stage as part of the preparation. Participant 1 reported: "they think it is very easy to put in the application, but when they see how [thorough] an ethics application process they, most of the time, get very scared of it. That can be a big barrier for our clinicians. Helping them understand that and helping them preparing for that in advance". Research facilitators also spoke about the emotional tensions among participants at the latter stage of the skills development program. Participant 5 noted the competition among the teams in their strive to get their proposals funded. In response, the research facilitator "look(ed) at the cost with them and their budget, and ... encouraged them to ... keep going with it even if they don't get the funding". Participant 9 recalled an example of a "very, very passionate clinician that ended up just throwing it in because it was just too hard". This was the most extreme example, highlighting that not all of the 
participants would go onto the next stage of the RRGP in terms of conducting the research studies. Dealing with unsuccessful proposals was on occasions the downside for the Research facilitator and the clinicians.

Overall, to use Participant 9's words, the research facilitators regarded the RRGP as being "a positive learning experience". Participant 1 emphasized the importance of sharing real-life examples during the workshops to make them relatable and engaging. She elaborated: "ethics week can be a really boring topic to cover, so I try to make it interesting by giving them real-life examples of situations that I've had with ethics applications, and make it more human, more emotional. These are things that happened to me, and usually it was because there were people involved with personalities, and this is something that I've learned". Research facilitators with clinical experience similar to some of the clinicians suggested its usefulness in terms of having shared reference points. For example, Participant 2 remarked: "when I talk about the clinical information, as I am a clinician also, the clinicians easily can get it and I'm hoping that - I'm sharing that with you now so that you can learn from it".

A sense of mutual commitment and investment between the clinicians and research facilitators emerged from the narratives. Research facilitators spoke about the time-consuming nature of RRGP participation for the clinicians in the voluntary, unpaid capacity. Reflecting on the estimated five to ten hour weekly clinician's commitment to the program, Participant 3 remarked: "I also get the feeling they do it as a sense of commitment to us research facilitators, that, you know, we are giving up loads of our time, that they should do the same, to get the best out of the project". Research facilitators spoke about investing their time in supporting clinicians outside the realm of the workshop hours. They spoke about their commitment to the program in terms of their commitment and fulfillment with mentoring novice researchers to conduct researchers, as well as the real-world significance of the implications of the RRGP research projects. Participant 9 summed up the reciprocity of investment: "without the research facilitators, the RRGP wouldn't exist and without that program, there's no platform for researchers to engage in research activities like those that are presented within the RRGP".

\section{Discussion}

Despite the recognition about the value of Research Capacity Building (RCB), the available research about the effectiveness of efforts for building research capacity in health care organisations is limited in scope (21-23). Historically, RCB interventions included provision of support to individuals rather than groups through fellowships, training schemes and bursaries $(6,24)$. The effectiveness of RCB interventions have focused on either identifying improvements in research skills of the individuals or the research outputs including journal publications, successful grant applications and conference presentations, outputs that are difficult for novice researchers to achieve $(24,25)$. Our study highlights the importance of the research facilitator role in terms of facilitating the research process and engaging expert clinicians as novice researchers. The RRGP research facilitator identified they achieved this by tapping into their theoretical research knowledge and drawing upon their practical experience of conducting research. The research facilitators identified their role as knowledge brokers who worked with the clinicians as novice 
researchers to simplify the research process and support them turning a clinical problem into a feasible research question and then keeping them on track while they developed their research proposal.

Facilitation has been popularized in health care as an innovation to bridge the chasm between knowledge generation and translation $(18,26,27)$. As a 'guided interactional process' $(26)$ and 'dynamic interplay between multiple individuals' (18), facilitation is relationship-based and involves interactions between research 'producers' and 'users' (28). Facilitation has evolved from a concept in the education and counselling literature to an implementation intervention in the healthcare and knowledge translation literature (27). Researchers describe facilitation as both a role (the facilitator) and a process $(18,26)$. Elledge, Avworo (18) report that in the healthcare literature, the term facilitator often describes an action, skill or contextual variable rather than an individual. Literature reports that roles such as the research facilitator can be a useful strategy in building the research capacity of health care clinicians $(24,29,30)$, however, there are gaps in understanding the potential of facilitation broadly (26), and how it can be particularly applied to build research capacity of clinicians. Attributes of successful research facilitators are not well described in the current literature (18). Much of the facilitation literature focuses on how facilitation is conceptually useful for the "doing" phase of integrating research findings into the organisational settings (26). However, simply creating knowledge in isolation does not drive clinical outcomes (18). Until now, little attention has been applied to developing an understanding of the characteristics of the research facilitator role and how this role contributes to clinicians' engagement in the research process. Our study reports on the characteristics of the research facilitator role in a research capacity building (RCB) model and explains how the role fosters clinicians' engagement with the research process.

The term 'knowledge broker' has been applied to various contexts in healthcare settings (31), but fundamentally, the term is most often understood to mean a person who connects science and society. Whilst numerous publications provide information about the desired characteristics of a knowledge broker when translating evidence to practice (32-35), currently, little is known about the qualities required of knowledge brokers in terms of building clinicians' research capacity. The RRGP research facilitators provided this study with rich and detailed data regarding the skills and attributes they believe are necessary when facilitating clinicians' engagement with the research process, presented in detail in Table 1.

There is evidence of RCB programs acknowledging health practitioners as a novice researchers that go on to mention the inclusion of research facilitators or mentors throughout the RCB program $(13,14,24$, 36-38). These studies cite various positive consequences of including a research facilitator/mentor role in the RCB programs, for example; the novice researchers felt more supported and valued the partnership (13), there was evidence of an improved research culture (24) and increased publication outputs attributed to the inclusion of the role (36). Whilst there was much written about the outcomes, there was limited information about the characteristics of the research facilitator when they were engaging with the expert clinicians as novice researchers. Results from our study will be useful when developing the position description for a research facilitator for future RCBs. Considering the amount of evidence 
highlighting the benefits of including a research facilitator in RCB programs, it is valuable to understand the responsibilities, skills and attributes required to fulfill the role.

Limitations of the study

Facilitators expressed a desire to continue to be involved in the program which may introduce a bias in how they self-reported and perceived the facilitator role. At the time of the interviews, most continued to be involved in the second phase of the program as mentors for funded research teams. Perhaps because the facilitators had already dedicated much time and put in a lot of work over an extended period of time, they saw their participation as a long-term investment in terms of developing industry research partnerships. Therefore, their appraisal of the facilitator role of the eight week course may have had a more long term focus.

\section{Conclusion}

There is evidence reporting more positive outcomes from research capacity building programs that include a research facilitator role and it has also been suggested that roles such as the research facilitator can be a useful strategy in building the research capacity of health care clinicians. However, until now, little attention has been applied to identifying the characteristics of the research facilitator role and how this role contributes to clinicians' engagement with the research process.

This study reports on the characteristics of the research facilitator role in a research capacity building (RCB) model in one regional hospital health service in Australia and explains how the role fosters clinicians' engagement with the research process. We found that the research facilitators' contribution can be characterised under two main themes: Facilitating the research process and Engaging expert clinicians as novice researchers. Analysis of data facilitated the identification of a table of responsibilities, skills and attributes required to fulfil the research facilitator role. This information will inform the development of future RCB programs and is important when you consider that clinicians' increased engagement with the research process is important for developing a sound evidence base to support decision-making in practice and leads to higher levels of skills and greater ability to perform useful research.

\section{Declarations}

\section{Ethics approval and consent to participate}

This project sought and received approval from Central Queensland Hospital and Health Service Human Ethics Committee (HREC), approval number HREC/2018/QCQ/46128

\section{Consent for publication}




\section{Availability of data and materials}

The datasets generated and/or analysed during the current study are not publicly available due to the material being related (in some instances) to patient admissions. However, de-identified data may be available from the corresponding author on reasonable request.

\section{Competing interests}

The authors declare that they have no competing interests.

\section{Funding}

The RCB program is jointly funded by Central Queensland University, Australia and Central Queensland Hospital and Health Service.

\section{Authors' contributions}

TF and TD contributed to all aspects of the paper, AS collected and analysed data, KRS and TS prepared and submitted ethics application and provided feedback to the development of the manuscript. JK assisted in data analysis and delivery of the RCBP.

\section{Acknowledgements}

Whilst the team composition has evolved since the original project commenced four years ago, the authors of this paper would like to acknowledge the investigators who contributed to the initial iteration of the program.

Professor Susan Kinnear, CQUniversity, Australia

Professor Corneel Vandelanotte, CQUniversity, Australia

\section{References}

1. Smith LS, Wilkins N. Mind the Gap: Approaches to Addressing the Research-to-Practice, Practice-toResearch Chasm. Journal of public health management and practice: JPHMP. 2018;24 Suppl 1 Suppl, Injury and Violence Prevention(Suppl 1 injury and violence prevention):S6-S11. 
2. Westerlund A, Sundberg L, Nilsen P. Implementation of Implementation Science Knowledge: The Research-Practice Gap Paradox. Worldviews on Evidence-Based Nursing. 2019;16(5):332-4.

3. Morris ZS, Wooding S, Grant J. The answer is 17 years, what is the question: understanding time lags in translational research. J R Soc Med. 2011;104(12):510-20.

4. Cooke J, Gardois P, Booth A. Uncovering the mechanisms of research capacity development in health and social care: a realist synthesis. Health Research Policy \& Systems. 2018;16(1):N.PAG-N.PAG.

5. Trostle J. Research capacity building in international health: definitions evaluations and strategies for success. Soc Sci Med. 1992;35(11):1321-4.

6. Cooke J. A framework to evaluate research capacity building in health care. BMC Family practice. 2005;6(1):44.

7. McIntyre E, Brun L, Cameron H. Researcher development program of the primary health care research, evaluation and development strategy. Australian Journal of Primary Health. 2011;17(1):114-21.

8. Graham ID, Logan J, Harrison MB, Straus SE, Tetroe J, Caswell W, et al. Lost in knowledge translation: time for a map? Journal of continuing education in the health professions. 2006;26(1):13-24.

9. H2020 Scientific Panel for Health. Building the future for health research - A consensus document of the H2020 Scientific Panel for Health. 2018.

10. Brauer SG, Haines TP, Bew PG. Fostering clinician-led research. Elsevier; 2007.

11. Alison JA, Zafiropoulos B, Heard R. Key factors influencing allied health research capacity in a large Australian metropolitan health district. Journal of multidisciplinary healthcare. 2017;10:277-91.

12. Higgins I, Parker V, Keatinge D, Giles M, Winskill R, Guest E, et al. Doing clinical research: the challenges and benefits. Contemporary Nurse. 2010;35(2):171-81.

13. McKee G, Codd M, Dempsey O, Gallagher P, Comiskey C. Describing the implementation of an innovative intervention and evaluating its effectiveness in increasing research capacity of advanced clinical nurses: using the consolidated framework for implementation research. BMC nursing. 2017;16(1):21.

14. Schmidt DD, Webster E, Duncanson K. Building research experience: Impact of a novice researcher development program for rural health workers. Aust J Rural Health. 2019;27(5):392-7.

15. Harbman P, Bryant-Lukosius D, Martin-Misener R, Carter N, Covell CL, Donald F, et al. Partners in research: building academic-practice partnerships to educate and mentor advanced practice nurses. J Eval Clin Pract. 2017;23(2):382-90.

16. Lee G, Metcalf S. Building research capacity: through a hospital-based clinical school of nursing. Nurse Educ Today. 2009;29(3):350-6.

17. Nicholson K, Ganann R, Bookey-Bassett S, Baird LG, Garnett A, Marshall Z, et al. Capacity building and mentorship among pan-Canadian early career researchers in community-based primary health care. Primary health care research \& development. 2020;21. 
18. Elledge C, Avworo A, Cochetti J, Carvalho C, Grota P. Characteristics of facilitators in knowledge translation: An integrative review. Collegian. 2019;26(1):171-82.

19. Moxham L, Taylor E, Dwyer T, Lauder W, Antoniou C, Roxburgh M, et al. Articulating expectations about post graduate supervision: Getting it right at the start of the journey. In: Fourie-Malherbe M, Albertyn R, Aitchison C, Bitzer E, editors. Postgraduate Supervision: Future foci for the knowledge society. African SUN MeDIA Stellenbosch; 2016. pp. 142-56.

20. Braun V, Clarke V. Using thematic analysis in psychology. Qualitative Research in Psychology. 2006;3(2):77-101.

21. Ewen SC, Ryan T, Platania-Phung C. Capacity building of the Australian Aboriginal and Torres Strait Islander health researcher workforce: a narrative review. Human Resources for Health. 2019;17(1):115.

22. Golenko X, Pager S, Holden L. A thematic analysis of the role of the organisation in building allied health research capacity: a senior managers' perspective. BMC Health Services Research. 2012;12(1):1-10.

23. Cooke J, Nancarrow S, Dyas J, Williams M. An evaluation of the Designated Research Team Approach to building research capacity in primary care. BMC Fam Pract. 2008;9.

24. Holden L, Pager S, Golenko X, Ware RS, Weare R. Evaluating a team-based approach to research capacity building using a matched-pairs study design. BMC Family Practice. 2012;13(1):16.

25. Cooke J, Nancarrow S, Dyas J, Williams M. An evaluation of the'Designated Research Team'approach to building research capacity in primary care. BMC Family Practice. 2008;9(1):37.

26. Berta W, Cranley L, Dearing JW, Dogherty EJ, Squires JE, Estabrooks CA. Why (we think) facilitation works: insights from organizational learning theory. Implementation Science. 2015;10(1):141.

27. Cranley LA, Cummings GG, Profetto-McGrath J, Toth F, Estabrooks CA. Facilitation roles and characteristics associated with research use by healthcare professionals: a scoping review. BMJ open. 2017;7(8):e014384.

28. Dobbins M, Robeson P, Ciliska D, Hanna S, Cameron R, O'Mara L, et al. A description of a knowledge broker role implemented as part of a randomized controlled trial evaluating three knowledge translation strategies. Implementation science. 2009;4(1):23.

29. Gagliardi AR, Webster F, Perrier L, Bell M, Straus S. Exploring mentorship as a strategy to build capacity for knowledge translation research and practice: a scoping systematic review. Implementation Science. 2014;9(1):122.

30. Burgess T, Farmer EA, Jones A, Waters R, Fuller J, Stocks N, et al. Building research capacity: An exploratory model of GPs' training needs and barriers to research involvement. Aus Fam Physician. 2003;32(11):957.

31. Thompson MR, Schwartz Barcott D. The Role of the Nurse Scientist as a Knowledge Broker. J Nurs Scholarsh. 2019;51(1):26-39.

32. Bornbaum CC, Kornas K, Peirson L, Rosella LC. Exploring the function and effectiveness of knowledge brokers as facilitators of knowledge translation in health-related settings: a systematic 
review and thematic analysis. Implementation Science. 2015;16:1-12.

33. Kislov R, Hodgson D, Boaden R. Professionals as knowledge brokers: the limits of authority in healthcare collaboration. Public Adm. 2016;94(2):472-89.

34. Newman K, DeForge R, Van Eerd D, Mok YW, Cornelissen E. A mixed methods examination of knowledge brokers and their use of theoretical frameworks and evaluative practices. Health Research Policy Systems. 2020;18(1):1-11.

35. van der Graaf P, Shucksmith J, Rushmer R, Rhodes A, Welford M. Performing collaborative research: a dramaturgical reflection on an institutional knowledge brokering service in the North East of England. Health Research Policy \& Systems. 2019;17(1):N.PAG-N.PAG.

36. Duncanson K, Webster EL, Schmidt DD. Impact of a remotely delivered, writing for publication program on publication outcomes of novice researchers. Rural Remote Health. 2018;18(2):4468-

37. Friesen EL, Comino EJ, Reath J, Derrett A, Johnson M, Davies GP, et al. Building research capacity in south-west Sydney through a Primary and Community Health Research Unit. Australian Journal of Primary Health. 2014;20(1):4-8.

38. Ward EC, Hargrave C, Brown E, Halkett G, Hogg P. Achieving success in clinically based research: the importance of mentoring. Journal of Medical Radiation Sciences. 2017;64(4):315-20. 